\title{
TENSIONES NAVIDEÑAS: CAMBIOS Y PERMANENCIAS EN LA CELEBRACIÓN DE LA NAVIDAD EN SANTIAGO DURANTE EL SIGLO XIX1
}

\author{
CHRISTMAS TENSIONS: CHANGE AND PERMANENCE \\ IN THE CELEBRATION OF CHRISTMAS IN SANTIAGO \\ DURING THE 19TH CENTURY
}

\section{OLAYA SANFUENTES ${ }^{2}$}

\section{RESUMEN}

A través del caso de la celebración de la Navidad en Santiago de Chile durante el siglo XIX, se develan los procesos de secularización y modernización, así como la privatización de la piedad y segregación social en las formas de celebrar. Estos procesos son altamente visibles a través de la discusión en la prensa decimonónica, donde vemos una compartida preocupación -entre liberales y conservadores- por el orden y la moral.

Palabras clave: Fiesta de Navidad, prensa en Chile, Iglesia en Chile, religiosidad, siglo XIX.

\section{ABSTRACT}

Through the case of the celebration of Christmas in Santiago de Chile during the nineteenth century, processes of secularization and modernization are shown, as well as the privatization of piety and the social segregation of traditions of celebration. These processes are highly visible in discussions in the nineteenth century press where we can observe a shared concern -both in liberals and conservatives- for order and morality.

Keywords: Christmas, Chilean Press, Chilean Church, religiosity, Nineteenth Century.

Recibido: 05.12.12. Aceptado: 09.03.13.

\footnotetext{
${ }^{1}$ El artículo aquí presentado se inserta en el marco del proyecto Fondecyt 1080210, "Frutales y Sociedad en Chile", del cual la autora es coinvestigadora.

${ }^{2}$ Académica Instituto de Historia Pontificia Universidad Católica de Chile. Santiago, Chile. E-mail: osanfuentes@gmail.com
} 


\section{INTRODUCCIÓN}

L

AS PALABRAS Y MELODÍAS del cantautor catalán Joan Manuel Serrat en su canción "Fiesta” nos iluminan y sugieren tópicos y características que la consolidan como una manifestación soberana de la cultura. Efectivamente, repasando y cantando los párrafos de Serrat podemos decir que la fiesta es: despliegue del ser sagrado y profano, un corte en la temporalidad cotidiana o hito en el tiempo ordinario, espacio temporal cualitativamente valioso donde todos logran ser y parecer otra cosa en una convivencia acompañada de una estética específica, para finalmente poder concluir cantando "Se acabó, el sol nos dice que llegó el final".

Con esta música de fondo podemos ir presentando nuestra celebración navideña en el Santiago del siglo XIX, al tiempo que iremos intentando demostrar que, a pesar del proceso de secularización (Serrano, 2008: 20) 3 y modernización que comenzará a experimentar la sociedad chilena, la Navidad se mantendrá hasta mediados del siglo XIX como una fiesta heterodoxa y con tintes barrocos. A partir de entonces, por modificaciones urbanas, influencias externas y cambios en la forma de concebir la piedad, la Navidad se irá transformando en una fiesta más privada y familiar, con tintes extranjeros y menos chilenos ${ }^{4}$.

Por la amplitud de los temas que aquí estamos sugiriendo, nos abocaremos a ver la transformación de la fiesta navideña desde mediados de siglo, a la luz de los cambios propuestos por las autoridades frente a un nuevo concepto de orden y como corolario de una nueva forma de ver la piedad desde Roma. En este proceso veremos que las preocupaciones por el orden son compartidas por las autoridades civiles y eclesiásticas e incorporan a la prensa como un nuevo protagonista en la discusión pública (Bernedo, $2006)^{5}$.

\footnotetext{
${ }^{3}$ Hemos tomado la idea de secularización de esta historiadora. Esta idea se aleja de la que la sociología clásica que parte de la base que la diferenciación de las esferas secular y religiosa llevaban necesariamente no solo la privatización sino la declinación de la religión. La evidencia ha mostrado que la religión siguió presente también en la dimensión pública.

${ }^{4}$ La fiesta de Navidad es, junto con el Dieciocho de Septiembre, la celebración más importante en Chile durante el siglo XIX. "Si hay algo que conmueva al pueblo, le entusiasme, le distraiga de sus tareas, de su vida común y monótona, es la pascua. De cuantas reconoce y celebra la iglesia como festividades, ninguna tiene una influencia tan grande". La Pascua, El Pueblo, La Noche Buena (1853, 26 de diciembre). El Diario, Valparaíso.

5 "Los periódicos se convirtieron en el soporte material de participación" (Bernedo, 2006: 103). Esta preponderancia que le damos a la prensa -como fuente así como actor dentro de la época-, no implica, por ningún motivo, que hayan desaparecido en el siglo XIX las formas tradicionales de comunicación de ideas. Solamente queremos relevar la importancia de este nuevo agente y su participación protagónica en las discusiones de la época.
} 


\section{LA CELEBRACIÓN DE LA NAVIDAD EN CHILE}

Las navidades coloniales fueron una instancia festiva que, al igual que muchas otras, compartían una naturaleza sensitiva y exteriorizante que podría denominarse barroca ${ }^{6}$. Si a esto le agregamos que la Navidad en Chile se daba en la época estival, en que la naturaleza pródiga desplegaba toda su fertilidad y bonanzas, la sensualidad, el gozo y las muestras de amor ponían el tono y, como dice Maximiliano Salinas, permitía que las navidades fueran bastante carnavalescas. Todo hacía de la Navidad un tiempo maravilloso, una concreta afirmación de la vida y de la renovatio mundi (Salinas, 2005: 139).

Como fiesta barroca, la Navidad sufrió también las intervenciones de la autoridad colonial que trataba de mantener un equilibrio entre dos necesidades: la de otorgarle al pueblo una instancia de derroche e inversión de su cotidianeidad, y la de cuidar el orden a través de un despliegue simbólico de la autoridad, donde imperaban las figuras de la Iglesia y el Rey. Con estos mecanismos complementarios, la fiesta lograba consolidarse en una vivencia popular que daba rienda suelta a los sentidos y al cuerpo en general, al tiempo que podía erigirse en un medio de control de masas para mantener un cierto orden y estabilidad.

\section{NAVIDAD EN EL SIGLO XIX}

Las características barrocas y religiosas ${ }^{7}$ de la Navidad capitalina se mantuvieron casi intactas durante gran parte del siglo XIX. Tanto la prensa como los viajeros que se acercaron y avecindaron en nuestro país, así como fotografías de época, nos muestran esta abigarrada celebración llena de estímulos y bastantes desórdenes. Durante muchos años la fiesta tenía su centro en la Plaza de Abastos, hasta que la magnitud que alcanzó obligó al intendente

\footnotetext{
${ }^{6}$ Nos inclinamos por las ideas de José Antonio Maravall (1983) respecto al Barroco. Al referirse a este fenómeno, tanto en Europa como en América, lo trata como un concepto de época, en que hay una relación indisoluble entre poder político y religioso y en que toda la sociedad se ve afectada. El Barroco lo entenderemos como una herramienta al servicio de la conservación de una visión de mundo y de una sociedad en tensión. Mediante recursos persuasivos se trata, al mismo tiempo, de persuadir y de acallar a la masa para mantener el orden.

${ }^{7}$ Entendiendo la fiesta religiosa como aquella con raíz sagrada, de carácter trascendente, que afirma la vida y la confraternidad entre los hombres (Cruz, 1992: 73). Más adelante, Cruz señala que para ella, las fiestas religiosas de origen colonial, mestizas, son las fiestas en el pleno sentido de la palabra.
} 
a trasladarla a la Alameda. Desde todos los lugares aledaños de Santiago llegaban los tenderos y venteros con sus frutas, flores, fritangas, horchatas, helados y dulces a instalarse a los costados de la Alameda y en ciertas calles aledañas para vender sus productos. El pueblo se paseaba y disfrutaba de la celebración, donde convivían -transversalmente- ricos y pobres, grandes y chicos, hombres y mujeres. Era una fiesta chilena y, como tal, fue muchas veces comparada con la del Dieciocho de Septiembre.

Todo este despliegue y derroche de recursos no era otra cosa que una demostración explícita de lo vívida y genuina que la celebración del nacimiento del Hijo de Dios era para los fieles decimonónicos. Cada vez que se celebraba Navidad, se participaba activamente en la conmemoración, en la vuelta a vivir el gozo que producía este evento fundante del cristianismo. La encarnación de Dios se entendía como un evento que afectaba inmediatamente la existencia de los hombres. Se la veía como una realidad histórica propiamente tal (Pieper, 1974: 34).

Por esta razón es que la visualidad de la celebración navideña siempre incluía elementos tomados de un tiempo y espacio contemporáneo y chileno. Efectivamente, las ofrendas navideñas eran aquellas que proporcionaban el campo chileno con sus cosechas estivales. Sandías, duraznos, frutillas, ciruelas y brevas son las frutas que crecen en los alrededores de Santiago, llegan en carretas hasta la capital y protagonizan comercios y regalos navideños. Flores y frutas se constituyen en las ofrendas al Niño Jesús en fanales y pesebres, así como eran el regalo preferido entre aquellos que se quieren. Los hombres regalaban albahaca a las niñas retacas y los duraznitos de la virgen y las brevas de la estación se regalaban a grandes y niños.

Es la importancia absoluta de la fiesta navideña en el sistema de valores de esta sociedad tradicional la que explica todo el derroche pero, al mismo tiempo, los desórdenes aparejados a la celebración. El acontecimiento es tan magno y su conmemoración tan genuina, que no hay área de la vida que no se afecte, ya sea mundana o religiosa (Pieper, 1974: 44).

Frente a todo esto, la jerarquía de la Iglesia hubo de reaccionar. Heredera de un reformismo eclesiástico del siglo XVIII con tendencias regalistas, la jerarquía eclesiástica chilena decimonónica reaccionó con distancia frente al culto tan exteriorizado que podía caer en supersticiones, emotividades, irracionalidades y suntuosidades (Serrano, 2006: 140). Hubo también reformismo dentro de la Iglesia que, en un primer momento ilustrado y luego ultramontano, defendió algunos elementos secularizadores para depurar expresiones consideradas profanas (Serrano, 2008: 24). Según Claudia Castillo (2008: 842), esta actitud de la jerarquía se debe también, al hecho 
de que vio la posibilidad de educar al pueblo como un conjunto de ciudadanos católicos. Ya no una masa informe sino miembros -católicos- de la sociedad civil.

La autoridad civil también se pronunciaba frente a los desbandes de las fiestas navideñas. En sus intentos de conseguir el orden y la vida civilizada, los desórdenes callejeros eran una preocupación.

Los desórdenes de las navidades decimonónicas eran muchos y de variada índole. Y la prensa se convertía en un campo de batalla compartido para debatir las ideas de sociedad. En una sociedad que se modernizaba y secularizaba, la prensa representaba la articulación de una opinión pública. En el contexto del nacimiento de la idea de libertad y derecho de opinión, la jerarquía de la Iglesia Católica aceptó las nuevas reglas del juego e incluso llegó a promoverlas. Además decidió utilizar algunas armas que eran tradicionalmente consideradas liberales (la cultura escrita), para no quedar atrás y así lidiar en igualdad de condiciones. Aunque, como dice Castillo (2008), el catolicismo fue adoptando "tambaleantemente" las ventajas de la prensa como herramienta de discusión pública. Sin embargo, la jerarquía se daba cuenta de que el púlpito, las prédicas y los soportes de una cultura visual barroca ya no eran suficientes para luchar contra otras ideas y modelos de sociedad. Había que alinearse en la formación de ciudadanos virtuosos. "El pueblo, para ser un sincero representante del catolicismo, debía ser virtuoso" (Castillo, 2008: 843).

De los excesos denunciados por la prensa, uno de los más importantes es el que se relaciona con el consumo excesivo de alcohol. En las fiestas navideñas, fondas y chinganas constituían los espacios predilectos del pueblo para celebrar después de los oficios religiosos y hasta altas horas de la noche. Era ahí donde los desórdenes y abusos morales suscitaban la preocupación de las autoridades. Sin embargo, sus derechos de instalación proporcionaban importantes ingresos a las municipalidades (Fernández, 2005: 549).

Algunos extranjeros también quedaron impresionados con ciertas escenas navideñas y, dejando muy en claro las diferencias de la aristocracia y del pueblo en sus formas de celebrar, comentaban que este último permanecía toda la noche en las ramadas de la Alameda cantando, bailando, comiendo, jugando y bebiendo "de forma realmente salvaje" (Treutler, 1958: 502). Algunos aristócratas sentían también repulsión por las formas populares de celebrar. Amalia Errázuriz (s.f.: 338), consideraba que las celebraciones navideñas en las calles santiaguinas eran repugnantes por los excesos de la bebida en el pueblo. 
Las intenciones de la élite de desligarse de las formas de celebrar del pueblo y los diversos intereses involucrados en el tema de la embriaguez no fueron, sin embargo, obstáculo para que las autoridades y la opinión pública a través de la prensa manifestaran su compartida preocupación. El año 1851 estalló una controversia entre el periódico El Progreso ${ }^{8}$ y La Revista Católica ${ }^{9}$, ya que el primero acusaba a la Iglesia por no velar ni fiscalizar la embriaguez acaecida durante la Navidad de 1850. La prensa católica se quejaba también de la negligencia civil para hacerse cargo de este problema, en que el "libertinaje del pueblo que ha bebido sin tasa hace caso omiso de la decencia que exigen las buenas costumbres"10.

Podríamos decir que, entre todos los desórdenes que una fiesta traía consigo, el de la embriaguez era concebida -tanto por la prensa católica como la liberal- como el peor de los vicios y el enemigo mortal de la moral y el orden. El beber llevaba a otras indecencias, propiciaba el gasto innecesario y terminaba con hombres tirados en las calles sin cumplir con sus deberes laborales y cívicos. Esto atentaba directamente contra los valores ilustrados del trabajo, el ahorro y el comportamiento ciudadano responsable que se quería inculcar entre el pueblo. Por esta razón es que las quejas frente a los borrachos de las fiestas de Navidad, desde todos los flancos de la prensa decimonónica, están sobrerrepresentadas.

Los sonidos navideños constituían, asimismo, un factor de desorden para las autoridades. Para la eclesiástica, el canto en lengua vulgar en la misa de aguinaldo implicaba algo intolerable. Hacia 1838, las autoridades eclesiásticas decían que no era posible que en las misas navideñas se escucharan las mismas entonaciones de los estrados, teatros y aun las de otros lugares de inmoralidad y corrupción. Mandaba, entonces, al provisor y vicario general que pusiera orden y que se cantaran solamente canciones aprobadas para las misas solemnes (Astorga, 1861: 53). Diez años más tarde, el arzobispo Rafael Valentín Valdivieso vuelve a insistir en este camino, preocupado por el tenor profano y popular que la celebración navideña seguía desplegando. Utiliza las categorías de inmoderación e impropiedad para describir lo que ocurre en estas fiestas e insiste en la importancia de velar por los ritos establecidos por la iglesia para evitar escuchar "cantares con entonaciones

\footnotetext{
${ }^{8}$ Creado en 1842, El Progreso fue el primer diario de Santiago. Aparecía todos los días del año.

${ }^{9}$ La Revista Católica aparece el 1 de abril de 1843 publicándose en forma interrumpida hasta 1874, cuando fue reemplazada por El Estandarte Católico, diario político dirigido por el clero, que a su vez fue reemplazado por El Porvenir. La Revista Católica fue reestablecida en 1892 con publicaciones quincenales.

${ }^{10}$ Sin título (1885, 27 de diciembre). El Chileno, Santiago.
} 
profanas, pífanos y otros instrumentos que imitan cantos de aves o gritos de cuadrúpedos, o cualquiera de las cosas que se han acostumbrado otras ocasiones y que rigurosamente no son prevenidas en las mencionadas rúbricas" (Astorga, 1861: 223-224).

Hay, asimismo, testimonios de viajeros que se impresionan con esta algarabía y ruidos animales en los templos. C. E. Bladh (1951: 55) describe las fiestas navideñas de Chile como "extrañas y exóticas" y cuenta que hasta las iglesias llegan las personas con gallinas y cerdos vivos que son golpeados para hacerlos cloquear y chillar. Otros tocaban pitos y cuernos o metían bulla con matracas produciendo un terrible ruido que duraba toda la noche.

Esta liturgia popular acompañada de un ritual genuina y ruidosamente carnavalesco era llamada la bullanga de Navidad (Salinas, 2005: 173). Se trataba de un ruido atronador constituido por imitaciones de animales variados, acompañado de pitos, silbatos, flautines. Era para recordar el establo en que había nacido el Niño Dios.

Hay también una preocupación respecto a controlar los excesos que tengan que ver con el cuerpo. En las calles santiaguinas la gente pululaba y paseaba sin rumbo, armando un torbellino de confusión con gritos y chillidos. La gente se empujaba y se perdía en calles y callejuelas, conformando una masa unida y compacta ${ }^{11}$. Se daban restregones, pellizcones y "otras impertinencias"12. Esto llevaba, muchas veces, a riñas y pleitos callejeros.

Pero nuevamente, la prensa de opinión mostraba su preocupación y decía que el intendente estaba consciente del problema y que ya vendrían tiempos sin inconvenientes y desórdenes y que la Pascua sería celebrada de un "modo digno" ${ }^{13}$. Pasada la Navidad, el mismo diario hacía una apología al intendente Tocornal, quien habría dado aires nuevos a la celebración trasladando las ventas a la Alameda desde la Plaza de Abastos. Se adoptaba así el modelo europeo del paseo ordenado por una calle ancha y señorial, con las ventas al costado dispuestas con todo orden y simetría. Alguna prensa destacó, entonces, el comportamiento del pueblo en la fiesta, argumentando que entraba lentamente un espíritu de orden y moderación. Alegre sin entrar en excesos, el pueblo celebraba mientras la policía observaba como espectadora, relataba El Ferrocarril ${ }^{14}$.

${ }^{11}$ Diversidades (1854, 26 de diciembre). El Diario, Valparaíso (Corresponsal en Santiago).

${ }^{12}$ Nacimientos (1855, 20 de diciembre). El Diario, Valparaíso (Corresponsal en Santiago).

${ }^{13}$ La Pascua en la Alameda (1856, 20 de diciembre). El Diario, Valparaíso (Corresponsal en Santiago).

${ }^{14}$ Noche Buena (1857, 25 de diciembre). El Ferrocarril, Santiago. 
Se ve que la prensa es el lugar para discutir el modelo de celebración y la idea de orden que los diferentes grupos defienden. Frente a los elogios de la prensa liberal, para esos mismos años, el conservador diario El Mensajero del Pueblo ${ }^{15}$ se quejaba, en cambio, de los excesos, acciones inmodestas, riñas, pendencias y embriagueces que se llevaban a cabo en la Alameda para el 24 de diciembre ${ }^{16}$. De la misma línea era El Estandarte Católico, que se quejaba de la cantidad de borrachos de las celebraciones de 1874 y las tildaba de verdaderas inmoralidades ${ }^{17}$. Hacia 1885 El Chileno volvía a quejarse del contraste entre las funciones religiosas de recogimiento y piedad en los templos religiosos y las orgías báquicas de la Alameda, sin que el intendente hubiera hecho algo al respecto ${ }^{18}$.

La prensa católica veía a la religión como garante de un orden en la mantención de un mundo basado en los valores modernizadores. Las fiestas de Navidad con todos los desórdenes a ellas aparejadas -y aquí descritasconstituían una muestra significativa de lo que podía ocurrir si el pueblo, alejado de la verdadera religión, se desbandaba en su actuar carnavalesco. Las malas costumbres eran combatidas desde todas las alas de la prensa porque se veían como una desgracia tanto para la Cristiandad como para la República. En este escenario, entonces, tanto liberales como conservadores parecían compartir un ideal común ${ }^{19}$.

\section{LA NUEVA PIEDAD}

Frente a todos los excesos heredados de una sociedad tradicional y de una piedad barroca, la jerarquía de la Iglesia irá tratando de imponer, a través de variadas herramientas, pero sobre todo apoyada en las posibilidades del impreso, un nuevo tipo de piedad ${ }^{20}$. Una piedad más íntima, individual,

${ }^{15}$ Semanario católico publicado entre 1870 y 1886.

${ }^{16}$ La Pascua del Niño Dios (1870, 24 de diciembre). El Mensajero del Pueblo, Santiago.

${ }^{17}$ Las Fiestas de la Pascua (1874, 26 de diciembre). El Estandarte Católico, Santiago.

${ }^{18}$ Sin título (1885, 27 de diciembre). El Chileno, Santiago.

${ }_{19}$ Podríamos decir que la prensa católica nace, entre otras razones, para combatir, básicamente, dos flancos donde ve peligro. En primer lugar, aquel escenario de crecimiento de grupos masones y protestantes, junto a tendencias "impías" encarnadas en los liberales. En segundo lugar, la prensa católica se enarbola como paladín de las buenas costumbres persiguiendo una idea de orden y moral, en este caso, compartida por varios grupos ilustrados de la sociedad.

${ }^{20}$ Esto, a pesar de la desconfianza inicial de la Iglesia frente a la proliferación del impreso, "ligándola a los libros impíos" (Serrano y Jaksic, 2000). 
menos exteriorizable, una piedad más familiar y menos colectiva ${ }^{21}$. El auspicio explícito de una lectura piadosa, no era otra cosa que, desde las estrategias de la Iglesia, la capitalización de las posibilidades del impreso. La prensa católica era su encarnación en el plano público, y el libro de piedad o rezos era su equivalente en el plano privado.

Un libro clave en este escenario lo constituía la Imitación de Cristo de Kempis, lectura obligatoria en el Seminario de Santiago y recomendado por la prensa como libro fundamental para ser un buen cristiano (Salinas, 2005: 128). Aquí y en otras lecturas piadosas se hablaba de la importancia de la oración individual como arma frente a los males del siglo. Más que dotar de herramientas doctrinarias, la nueva piedad quería llegar al corazón y al intelecto del fiel para lograr su verdadero convencimiento. A diferencia de la experiencia barroca festiva comunitaria, en la experiencia piadosa de lectura y de devoción, el único testigo era el libro (Cherniavsky, 2008). Pero el impreso religioso se introducía en la piedad chilena en un período donde casi la mitad de la población seguía siendo analfabeta. Por eso es que todavía imágenes y estampas ayudaban mucho a la oración.

A lo largo del siglo XIX proliferaron los textos religiosos destinados a ayudar a rezar a los fieles. Se les llamaba devocionarios. Pero fueron las novenas el género más frecuentemente adoptado por los impresos piadosos destinados a devociones particulares. Esta era una forma textual surgida a principios de la Edad Media en Francia y España que, como lo dice su nombre, consistía en el rezo durante nueve días seguidos de una determinada devoción con el propósito de conseguir algún favor o gracia para prepararse para la celebración de un acontecimiento especial. Estaban asociados a una práctica de lectura intensiva. Suponían una lectura personal, de forma colectiva o individual, en la casa o en una iglesia. Eran baratas de conseguir (Cherniavsky, 2008: 214).

Hemos encontrado un cuerpo importante de novenas de Navidad para el siglo XIX. Impresos en el extranjero o bien en Chile por las cofradías religiosas, estos documentos permitían una preparación espiritual para el esperado acontecimiento del nacimiento de Cristo. Era, por una parte, una práctica bastante femenina, porque la mayoría de ellas comienza dedicándose a las fieles devotas. Hay algunas que se recomienda rezar en familia y,

21 "Celebra el nacimiento del Niño Dios, yendo al templo, a tomar parte en esas hermosas fiestas de la noche y de la mañana. Júntate con buenos cristianos, pasa un día tranquilo con tu esposa y tu familia”. La Pascua del Niño Dios (1870, 24 de diciembre). El Mensajero del Pueblo, Santiago. 
por otra parte, fuentes documentales complementarias (fotografías, cuadros y prensa), nos sugieren que su rezo estuvo bastante extendido en los templos y hogares del siglo XIX.

Algunas de estas novenas se rezaban al frente de una imagen votiva, que en el caso chileno solían ser tallas quiteñas llegadas a Chile durante el siglo XVIII y bastante populares durante todo el siglo XIX. Sabemos también de la llegada de esculturas religiosas desde Europa y de la fabricación nacional de tallas de madera y de yeso. Todo esto no viene sino a demostrar la demanda particular por imágenes votivas.

Las novenas se rezaban en comunidades de diferentes tamaños. Podían seguirse novenas en los templos de la ciudad, en los conventos de monjas o bien en familia.

Tenemos registro de llamados a rezar la novena de Navidad en diferentes parroquias durante casi todo el siglo XIX. En todas ellas se rezaba la novena y leían libros devocionarios; luego se cantaban villancicos y se hacían procesiones dentro de la iglesia.

Los impresos piadosos dedicados a devociones particulares dan cuenta de una piedad romántica con grandes dosis de emotividad, tal y como lo había sido la piedad barroca, pero que a diferencia de ésta, ponía su acento en la oración interior, personal e individual a través del método de oración mental. Esto era en parte expresión de la fuerte influencia recibida de la espiritualidad francesa contrarreformista a través de las congregaciones religiosas que se habían instalado en el país a partir de la década del cuarenta. Pero también esta piedad afectiva, íntima y sentimental, opuesta al racionalismo y al intelectualismo que caracterizará a la piedad católica chilena de mediados de siglo, fue fomentada y propagada desde Roma (Cherniavsky, 2008: 217).

\section{NUEVAS FORMAS DE CELEBRAR}

Van surgiendo a finales del siglo XIX nuevas formas de celebrar la Navidad que también hablan de un cambio de foco y de aspectos tendientes a la privatización de las prácticas votivas, así como a una segregación social en el espacio urbano.

La aristocracia comienza a organizar fiestas privadas con bailes de máscaras para el mismo día 24, con la excusa de satisfacer las necesidades de una "decente juventud"22. Hacia 1870 una revista católica conservadora ha-

${ }^{22}$ Sin título (1878, 17 de diciembre). Las Novedades, Santiago. 
bla de la celebración de la Navidad de algunas familias "verdaderamente cristianas", donde el padre, la madre y los hijos arrodillados delante de una imagen del niño, recitan oraciones y cantan villancicos. El contraste con la otra forma de celebrar, la profana y popular queda explícita: "La Plaza de Abastos, la Alameda, ¿no son testigos de acciones inmodestas, de riñas, pendencias, embriagueces y otros cien actos tan punibles como estos?"23, argumentaba la publicación de tinte conservador.

El año 1878 un particular propone hacer una fiesta en su casa, prometiendo orden y moderación ${ }^{24}$. Hacia 1895 un grupo de mujeres de la aristocracia organizaba para Navidad una kermesse de beneficencia en la Quinta Normal, a la que habría concurrido gente muy distinguida ${ }^{25}$. Paralelas a estas fiestas particulares y privadas, seguirán organizándose las fiestas públicas y populares en la Alameda ${ }^{26}$ y en otros barrios, como de San Isidro y San Diego. En esos lugares los cantos y bailes populares se prolongaban toda la noche hasta el amanecer a través de puestos de frutas, flores y dulces. Se bailaban zamacuecas al son de arpa y guitarra ${ }^{27}$. Las cantoras lucían vistosos trajes llenos de cintas y blondas y entonaban sus villancicos, aguinaldos y tonadas a María y al Niño Jesús.

Como se puede apreciar a través del caso concreto de la celebración de la Navidad, asistimos a un proceso de segregación social del espacio urbano, o "segregación espacial según estratos sociales", como denominó Armando de Ramón (citado en Vicuña, 1996: 46) a este proceso. Había una relación entre las nuevas formas de celebrar y socializar y el aspecto y disposición del espacio urbano desde mediados del siglo XIX. Como consecuencia de la introducción y adopción de los nuevos valores modernizadores, una suerte de individualismo envuelve a las manifestaciones culturales decimonónicas. Las nuevas concepciones de la sociedad orientaban hacia el progreso material y el gozo íntimo en un paisaje culturalmente creado. Esto se va imponiendo sobre la tradicional valoración comunitaria y socialmente abierta de los espacios públicos (Méndez, 1994-1995: 257). Un ejemplo concreto es la nueva utilización que se dio al Campo de Marte, antaño lugar de celebración absolutamente transversal, donde todos se juntaban a celebrar. Con

${ }^{23}$ La Pascua del Niño Dios (1870, 24 de diciembre). El Mensajero del Pueblo, Santiago.

${ }^{24}$ Sin título (1878, 19 de diciembre). Las Novedades, Santiago.

${ }^{25}$ Las Fiestas de Pascua (1895, 25 de diciembre). El Porvenir, Santiago.

26 "El paseo de las Delicias fue anoche visitado por una concurrencia inmensa de gente, en su mayoría del pueblo”. La Avenida de las Delicias (1888, 25 de diciembre). El Chileno, Santiago.

${ }^{27}$ Sin título (1878, 26 de diciembre). Los Tiempos, Santiago. 
Luis Cousiño se convertirá en parque y se abocará a deleitar, casi exclusivamente, a la élite santiaguina (Vicuña, 1996: 47).

Otro síntoma de la segregación social del espacio urbano lo constituye la aparición de palacios de la aristocracia en lugares de los que termina apropiándose. La Quinta Normal, el parque Santa Lucía, el Club Hípico son los sectores elegidos por las familias Errázuriz Cousiño, Edwards, Larraín Zañartu, Urmeneta, Díaz Gana, Ossa para construir mansiones monumentales nunca antes vistas en nuestra capital. La oligarquía, en su afán por disfrutar su refinamiento y lujo, se alejaba del pueblo, como una forma de demostrar sus diferencias de estilo de vida y gustos.

Estas tendencias urbanas influían, obviamente, en los lugares elegidos y tácitamente establecidos para celebrar la Navidad: la oligarquía tendería a celebrar en lugares privados y alejada de los arrabales, mientras el pueblo seguiría ocupando el espacio público, pero más alejado de la oligarquía.

La celebración en la intimidad de los hogares seguía siendo alrededor de un nacimiento o pesebre. Si bien antes éstos tenían un carácter más bien público, donde una comunidad extendida se acercaba a ofrendar, la preparación y las prácticas votivas asociadas a los nacimientos también participan de la tendencia a la privatización. A comienzos y mediados del siglo XIX sabemos de correrías por los diferentes nacimientos de las iglesias, conventos y casas particulares que se exponían a la comunidad que apreciaba sus tallas quiteñas o la imaginación popular para adornarlos. Había una suerte de competencia entre los conventos, iglesias y casas particulares por exhibir el mejor nacimiento. Para finales de siglo asistimos a citas que hablan de una preparación más familiar de los pesebres. Existe, asimismo, un precioso cuadro de Arturo Gordon donde se respira un ambiente de devoción y recogimiento en el rezo de la novena ante un pesebre.

Se ve claramente, en las iniciativas de la jerarquía de la Iglesia Católica decimonónica, el deseo y el esfuerzo por disciplinar las prácticas religiosas, tanto en el ámbito público como en el privado. Este esfuerzo se intensifica a mediados del siglo XIX, con la gestión del arzobispo de Santiago -Rafael Valentín Valdivieso- desde 1847 y con la ayuda de La Revista Católica. Sin embargo, esta preocupación no es privativa del ámbito eclesial: la autoridad civil también la comparte. El intendente José Miguel de la Barra decía que las costumbres de la ciudad eran un deber tanto del Estado como de la Iglesia, lo cual es elocuente de la presión del Estado por quitar la exclusividad de la Iglesia en la esfera pública. 


\section{CONCLUSIÓN}

En la esfera pública -y concretamente en la fiesta de la Navidad que hemos utilizado como caso emblemático- tanto la prensa católica como la liberal abogan por un orden entendido como moral ${ }^{28}$. La moral es decencia, compostura y buenas costumbres. Trae aparejadas moderación y organización, conceptos tan caros para la vida en sociedad y la formación de ciudadanos. En el ámbito de la devoción privada, diversas corrientes irán produciendo una privatización de la piedad en el siglo XIX. Sol Serrano (2006) explica este proceso enriqueciendo y complejizando el término. Para ella, la religión se privatizó en el sentido de que progresivamente fue expulsada del Estado y redefinió su lugar en el reordenamiento del espacio público tradicional y moderno, de las calles, de la política, de la opinión y del debate. Sin embargo, continuó teniendo presencia pública en el culto colectivo. En la segunda vertiente, la religión se privatizó en el sentido de que se hizo más interior, íntima, familiar (Serrano, 2006: 153).

Creemos que con las fuentes hemos podido mostrar estas dos tendencias. Por un lado la forma de celebrar la Navidad fue acomodándose a los nuevos escenarios políticos y urbanos del Santiago de finales del siglo XIX, lo que terminó por generar una segregación en la forma tradicional de celebrar la Navidad. Ya no fue más una celebración masiva y transversal, en un espacio urbano compartido sino que para la mayoría quedó confinada a ciertos lugares públicos autorizados y tildada desde entonces como religiosidad popular. Son resabios vivos de ese catolicismo barroco colonial. Por otra parte, las autoridades favorecieron las prácticas más privadas e individuales frente a las públicas y colectivas en lo que a devoción se refiere.

\section{REFERENCIAS}

Astorga, J. R. (1861). Boletín eclesiástico o sea colección de edictos, estatutos $i$ decretos de los prelados del Arzobispado de Santiago de Chile. Tomo I. Santiago, Chile: Imprenta de la Opinión.

Bernedo, P. (2006). "Prensa e Iglesia en el Chile del siglo XIX. Usando las armas del adversario". Cuaderno de Información 19. Disponible en: http://fcom.al-

${ }^{28}$ No encontramos mayores diferencias en las definiciones de orden que proporcionan la prensa católica y la liberal para el caso de las celebraciones navideñas. Quizás la única diferencia es que, cuando se habla de excesos que son asociados con el desorden, la prensa liberal ataca a los católicos por permitir que el pueblo incurra en gastos inmoderados para estas celebraciones. Los derroches festivos son considerados desórdenes que no colaboran en el progreso. 
tavoz.net/prontus_fcom/site/artic/20061201/pags/20061201 122822.html

Bladh, C.E. (1951). La República de Chile, 1821-1828. Santiago, Chile: Imprenta Universitaria.

Castillo, C. (2008). "La fe en hojas 'de a centavo': Prensa Católica en Chile, sus lectores y el caso del Mensajero del Pueblo, 1870-1876". Teología y Vida Vol. 49 , No $4,837-874$.

Cruz, I. (1992). "Una instancia de sociabilidad pública: el legado de la fiesta religiosa barroca en Chile a principios del siglo XIX". En Agulhon, Maurice et al., Formas de sociabilidad en Chile, 1840-1940 (pp. 73-95). Santiago, Chile: Editorial Vivaria.

Cherniavsky, C. (2008). La religión en letra de molde: Iglesia y lectura en la Arquidiócesis de Santiago, 1843-1899. Tesis para optar al título de doctor en Historia. Profesor guía: Sol Serrano. Santiago, Chile: Pontificia Universidad Católica de Chile.

Errázuriz, A. (s/f). Mis días de peregrinación en Oriente. Santiago, Chile: [s.n.]. Fernández, M. (2005). Historia social del alcoholismo en Chile 1870-1930. Politicas, prácticas, representaciones. Tesis para optar al grado de doctor. Santiago, Chile: Pontificia Universidad Católica de Chile.

Maravall, J. A. (1983). La cultura del barroco. Análisis de una estructura histórica. Barcelona, España: Editorial Ariel.

Méndez, L. M. (1994-1995). "El espacio urbano en Chile. Tradición y cambio 1840-1990”. Notas Históricas y Geográficas 5-6: 255-256.

Pieper, J. (1974). Una teoría de la fiesta. Madrid, España: Ediciones Rialp.

Salinas, M. (2005). Canto a lo divino y la religión popular en Chile hacia 1900. Santiago, Chile: Lom Ediciones.

Serrano, S. (2006). "La privatización del culto y la piedad católicas". En Sagredo, R. y C. Gazmuri (eds.), Historia de la vida privada en Chile, Tomo II. El Chile moderno. De 1840-1925 (pp. 139-155). Santiago, Chile: Editorial Taurus.

(2008). ¿Qué hacer con Dios en la República? Política y secularización en Chile (1845-1885). Ciudad de México: Fondo de Cultura Económica.

Serrano, S. y Jaksic, I. (2000). "El poder de las palabras: La Iglesia y el Estado liberal ante la difusión de la escritura en el Chile del siglo XIX". Historia, Vol. 33, Santiago. Doi: 10.4067/S0717-71942000003300010.

Treutler, P. (1958). Andanzas de un alemán en Chile, 1851-1863. Santiago, Chile: Editorial del Pacífico.

Vicuña, M. (1996). El París americano. La oligarquía chilena como actor urbano en el siglo XIX. Santiago, Chile: Universidad Finis Terrae.

Periódicos

El Chileno, Santiago. Revisado entre 1883-1902.

El Diario, Valparaíso. Revisado entre 1851-1858.

El Estandarte Católico, Santiago. Revisado entre 1874-1890.

El Ferrocarril, Santiago. Revisado entre 1857-1879. 
El Mensajero del Pueblo, Santiago. Revisado entre 1870-1886.

El Porvenir, Santiago. Revisado entre 1891-1906.

Las Novedades, Santiago. Revisado entre 1877-1880.

Los Tiempos, Santiago. Revisado entre 1877-1882. 